\title{
worldview
}

A JOURNAL OF RELIGION AND INTERMATIONAL AFFAIRS

\section{INVESTIGATE THE UNITED NATIONS?}

India's "invasion" or "liberation" of Goa has raised questions which have yet to be resolved on either a practical or a theoretical level. To say nothing of the reaction of the Afro-Asian countries, this act of military aggression calls for more than the qualified approval or shocked disapproval with which it was initially greeted in most of the Western world. This act has exacerbated and forced into acrimonious debate questions which carry a threat to the viability and, indeed, the very existence of the UN.

There are real and severe problems engendered by a dving colonialism and the subsequent rise of many new nations; by the formation of an Afro-Asian bloc in which color has political meaning; by the changing character of the UN, which partially creates and partially reveals new relations among those nations which belong to it. India's action prompted many people to see these problems in a new light and, frequently, to criticize the general direction that has been followed in coping with them. Among these criticisms, the most vigorous and substantial attack was undoubtedly that delivered by Britain's Foreign Secretary. Why is there a "crisis of confidence in the United Nations?" Lord Home answered his own question in these terms: "The answer is that, for the first time since its foundation, a number of countries have voted publicly and without shame in favor of the use of force to achieve national ends." And he expanded the basis of his attack by criticizing the "reckless" resolutions on colonialism that have been passed by the General Assembly.

Lord Home's arguments are of crucial importance not alone because of the prominence of his position. For his arguments are shared by many who are unhappy with the direction of contemporary history and who believe they discern the reasons why it has set itself on its present particularly unhappy course; his vision is shared by those who find in the nineteenth-century balance of powers a paradigm for present political decisions and judgments. This is not necessarily fatal or even damaging to his position, as some critics suggested. All change is not for the better and there is neither an ethical nor a political imperative which savs we must work for the inevitable or be thankful when it arrives. It is not immediately apparent, for example, that the rapid increase in newly independent ex-colonial nations is an undiluted good. But neither is the converse a self-evident truth.

It is at this point that the issue is joined. There can be no serious debate that in the UN are focussed some of the most pressing and durable of our political problems, and that the grounds for confidence in the UN are being reexamined. The Congo, with its entangled roots and uncertain development, presents these problems in an even more distressing and potentially dangerous form than did the invasion of Goa. We can remain confident that in the future other related incidents will disturb the UN and divide opinion concerning its value. But if these issues are beyond debate others clearly are not. Lord Home's emphasis upon selected aspects of the UN charter reveals a definite tendency to favor the perpetuation of the international status quo. Intimately related to the question of whether such perpetuation is-or was ever intended to be-the function of the $\mathrm{UN}$, is the question of whether today it is possible or even desirable.

Such questions, rather than the list of particular complaints sometimes drawn up against the UN, lie behind the present demands for an investigation. Supporters of the UN should not be the last to welcome an investigation. It may be that even past fervent supporters will wish to modify their support. Or it may be that they will find renewed cause for support, that an investigation will reveal more sharply the shifting patterns of powver and interest to which the $U N$ is reacting. Such an inquiry would, of course, inevitably lead to an examination of the direction and purpose of United States foreign policy. But that can only be an additional reason for welcoming an investigation of the UN. 